\title{
Lo social y lo político en Chile: Itinerario de un desencuentro teórico y práctico
}

The social and politics in Chile: theoretical and practical disagreement

\author{
Mónica Iglesias Vázquez*
}

\begin{abstract}
Resumen
En este artículo sostenemos que el origen de la escisión entre lo social y lo político que se aprecia en la actualidad debe rastrearse en el modelo de transición a la democracia, que legitimó, en esencia, el modelo de sociedad que la Dictadura trató de imponer a sangre y fuego, buscando revertir las transformaciones económicas, sociales y políticas que trató de implementar el Gobierno de la Unidad Popular $\mathrm{y}$, muy especialmente, las experiencias de poder popular, que cuestionaban precisamente aquella escisión.
\end{abstract}

Palabras clave: poder popular, dictadura, transición a la democracia, lo social, lo político.

\begin{abstract}
We argue that the origin of the split between the social and the political that is seen today must be traced in the model of transition to democracy, that legitimized, in essence, the model of society that the dictatorship tried to impose blood and fire, seeking to reverse the economic, social and political transformations that the Unidad Popular Government tried to implement and, in particular, the experiences of popular power, questioning precisely that division.
\end{abstract}

Keywords: popular power, dictatorship, transition to democracy, the social, the political.

\footnotetext{
* Española. Licenciada en Sociología por la Universidad de Barcelona, Maestra en Estudios Latinoamericanos por la Universidad Nacional Autónoma de México y candidata a doctora por el mismo programa de estudios. Correo: monicaiglesias@ hotmail.com
} 
En Chile, los movimientos sociales existen poco, porque los partidos existen mucho y tienden a dominarlos.

(Moulian 2008: 170)

Cuando en agosto de 2012 la entonces dirigente estudiantil, Camila Vallejo, criticó a los diputados que habían votado a favor de una reforma tributaria regresiva, mientras decían apoyar al movimiento social, Pepe Auth, diputado del Partido por la Democracia (PPD) aseveró: "Yo no sigo instrucciones de nadie". ${ }^{1}$ Cuando el diputado Gabriel Boric decidió marchar con los estudiantes, el pasado 8 de mayo, ausentándose de la Cámara, fue sancionado por esa institución por haber abandonado sus funciones legislativas sin una causa justificante. En su respuesta, el diputado señaló: "No es extraño que algunos se escandalicen con la asistencia a una marcha, pues durante más de veinte años el abismo entre lo social y lo político lo ha hecho, para ellos, inimaginable". ${ }^{2}$ Ambos hechos confirman una apreciación generalizada en el Chile actual: la política se ha autonomizado de las luchas sociales. Pero ¿cuándo y cómo se extremó y legitimó esa escisión?

Sin lugar a dudas, la Dictadura provocó un ensanchamiento de la distancia que ha existido históricamente entre lo social y lo político, debido a las prohibiciones, exclusiones y desapariciones múltiples que produjo, sin perjuicio de que con anterioridad al golpe de Estado se verificaran marginaciones de ciertos grupos sociales respecto de la participación y representación políticas. Los militares desgarraron el tejido social, proceso que se valió de la anatemización de la política, e instauraron un modo de producción de actores políticos escindidos de lo social-popular. Las transformaciones económicas y políticas y el régimen de terror que impuso Pinochet, destinado a disciplinar la sociedad, destruyeron la matriz sociopolítica clásica y acabaron con la forma tradicional de hacer política. Aun así, emergieron en ese contexto, en condiciones de autonomización forzada, organizaciones y movilizaciones con gran protagonismo de los sectores populares, para enfrentar los efectos más perversos del sistema de exclusión económica, social y política; sin embargo, las organizaciones sociales no fueron capaces de restaurar la vieja forma de articulación con los partidos políticos, ni de instaurar una nueva. Las dificultades de la vinculación socio-política en aquel periodo fueron consideradas por algunos sociólogos e historiadores sociales (Baño 1985; De la Maza y Garcés 1985, entre otros).

Más incomprensible ha resultado el hecho de que el retorno de la democracia política no trajera aparejado un fortalecimiento de los movimientos sociales. El sentido

\footnotetext{
${ }^{1}$ La Segunda, 9 de agosto de 2012, p. 16.

${ }^{2}$ Misiva publicada en www.elmostrador.cl, 13 de mayo de 2014. Cabe señalar que, posteriormente, se revisó la decisión y se resolvió que "la participación en marchas ciudadanas [...] son causa justificante de una inasistencia" (Acuerdo No 75-2014, de 2 de julio de 2014).
} 
Mónica Iglesias V., Lo social y lo político en Chile: Itinerario de un desencuentro teórico y práctico / The social and politics in Chile: theoretical and practical disagreement, Revista Izquierdas, número 22, enero 2015, ISSN 0718-5049, Santiago de Chile, pp. 227-250

común y el discurso concertacionista hacían prever, efectivamente, "el reencuentro de sectores sociales y políticos" (Garretón 1986a: 17): "Lo lógico era suponer que el actual proceso político se apoyaría en la fuerza del pueblo movilizado" (Cárdenas 1991: 3). Por el contrario, los Gobiernos de la Concertación de Partidos por la Democracia evidenciaron, progresivamente, su profundo vaciamiento social; y la institucionalidad democrática se mostró como la "cáscara vacía" que había presagiado el politólogo Norbert Lechner (1987: 259). Tras el asombro inicial, algunos autores elaboraron trabajos que dan cuenta de la transmutación de la política en una actividad carente de sentido histórico, ensimismada y fetichizada, y de la pérdida de centralidad de los movimientos sociales: "Digámoslo de una vez. Lo que más llama la atención en los últimos años es la ausencia de conflictividad en la sociedad; tanto que parece que los movimientos sociales hubieran desaparecido" (Espinoza 2000: 207). ${ }^{3}$ En ese sentido, se ha hablado de un "segundo disciplinamiento" del mundo social (Guerrero 2006), que favoreció la desarticulación de los movimientos sociales que durante la Dictadura habían desempeñado un papel relevante. Sin embargo, compartimos con De la Maza la tesis de que "contrariamente a la imagen corriente, el diseño de la transición política chilena de fines de los años ochenta contemplaba como prerrequisito la desactivación de los movimientos sociales antidictadura que la habían hecho posible" (1999: 377). Aquel diseño buscó dotar de cientificidad la separación entre democracia política y democratización social, justificando la sujeción y la postergación de la segunda; de esa manera se avaló la elitización de la política y la subordinación y/o criminalización de lo social. $^{4}$

\footnotetext{
${ }^{3}$ Algunos estudios han señalado cómo, de manera concomitante, la lógica mercantilista colonizó la esfera pública y trastocó la naturaleza de la política, al convertir el vínculo de los ciudadanos con el gobierno en una relación entre clientes y proveedores de servicios. Por esa vía se habría producido la desvalorización de la participación política, equiparándola con un acto de consumo (Streeck, 2012). Para un análisis de los efectos de esa "contaminación" de la actividad política en el caso chileno, véase Lechner (1994) y Moulian (1997).

${ }^{4}$ Las nociones de "lo social" y "la política" han sido construidas por las ciencias sociales como dos esferas -en sentido figurado y real-y lógicas de acción social diferenciadas. Lo social se refiere a la red de relaciones que articula a los distintos actores sociales, configurando un entramado de prácticas y de significados que construyen y transforman los propios marcos materiales desde los que se erigen. En contraposición, la política alude a una esfera particular de relaciones, actividades e instituciones, por medio de las cuales los individuos y los grupos intervienen en los asuntos públicos, articulando, negociando, implementando y haciendo valer sus intereses sobre el conjunto de la sociedad y, por ende, valorando el orden social e imaginando otros órdenes posibles. Desde esta perspectiva sólo lo que sucede en esta esfera es político, mientras que las prácticas sociales que no se insertan en ella son definidas como apolíticas o no-políticas y, por lo tanto, carentes de legitimidad para, o incapaces de, proponer una configuración distinta de la sociedad.

A su vez, una veta del pensamiento filosófico propone la distinción entre "lo político" y "la política", para cuestionar precisamente la reducción de la función política a una esfera diferenciada y altamente institucionalizada. De manera muy somera, la diferencia puede ser formulada así: "Lo político posee un carácter sustantivo y una función instituyente, mientras que la política supone una lógica instrumental de administración de lo instituido" (Retamozo 2009: 79). La diferenciación entre lo político y la política permite cuestionar, por un lado, la autonomía de la política y, por otro, la despolitización de todas las prácticas sociales que se sitúan fuera de la esfera política. Si bien esta
} 
En este artículo sostenemos que la ruptura entre lo social y lo político que se aprecia en la actualidad, no se debe exclusiva o principalmente a factores acaecidos durante la posdictadura o a una suerte de traición de los líderes políticos que capitalizaron los designios de democratización de los sectores populares. Por lo tanto, tampoco es correcto hablar de "flaqueza" o "pusilanimidad" de los partidos de la Concertación. La raíz de esa escisión se encuentra en el propósito explícito de la Dictadura de reconfigurar la sociedad para volver a la política de los consensos entre élites, que durante la Unidad Popular (UP) se vio en peligro y, más claramente, en el compromiso que asumió la Concertación con aquel modelo, legitimando la escisión sobre la base de consideraciones de realismo político. Para desarrollar esta hipótesis, dividimos el argumento en tres momentos: 1) Los gérmenes de poder popular que durante la UP tensaron la escisión entre lo social y lo político, ensayando formas de organización que desdibujaban la separación; 2) El proyecto societal y la práctica política y económica de la Dictadura que forzó la desarticulación socio-política; 3) La consumación de la transición pactada a la democracia que subsumió y legitimó el modelo dictatorial. Por último, apuntamos algunas consideraciones a propósito de la necesidad de religar lo social y lo político, superando la concepción estrecha de la política y recuperándola para los proyectos de transformación radical de la sociedad.

\section{La escisión tensada}

"Luchar, crear, poder popular" fue una de las consignas más coreadas durante el período de la Unidad Popular. No se trató sólo de un eslogan en una pancarta o un grito en una manifestación; encarnó prácticas concretas y proyectos de transformación radical de las relaciones sociales imperantes que, hacia el ocaso de aquellos mil días, pusieron en entredicho el propio Gobierno de Salvador Allende y constituyeron una profunda preocupación para los "dueños de Chile", más aun que la "vía chilena al socialismo", porque la derecha entendió que "el principal peligro que amenaza el orden social y la propiedad privada de los medios de producción se sitúa precisamente en esta 'Revolución desde abajo', en gestación" (Gaudichaud 2004: 49).

El triunfo electoral de la UP el 4 de septiembre de 1970 significó el arribo al Gobierno de una coalición de partidos de izquierda; sin embargo, como recordaba a menudo Allende (1973a: 3): "Los trabajadores de Chile han conquistado el Gobierno; no han conquistado el poder". La idea de "poder popular" estaba presente en el programa de la UP; no obstante, su formulación guardaba una gran vaguedad,

\footnotetext{
distinción analítica nos parece útil, para efectos de este artículo lo político y la política deben ser considerados como sinónimos, con el propósito de no desviar la atención de la escisión que nos interesa rastrear.

${ }^{5}$ Expresión que empleara, sin embozo, en las postrimerías del siglo XIX, Eduardo Matte, político liberal e integrante de una de las familias más acaudaladas del país: "Los dueños de Chile somos nosotros, los dueños del capital y del suelo; lo demás es masa influenciable y vendible; ella no pesa ni como opinión ni como prestigio" (citado en Carmona 2002: 116).

${ }^{6}$ El concepto de "Revolución desde abajo" ha sido empleado, entre otros, por Winn (2004).
} 
Mónica Iglesias V., Lo social y lo político en Chile: Itinerario de un desencuentro teórico y práctico / The social and politics in Chile: theoretical and practical disagreement, Revista Izquierdas, número 22, enero 2015, ISSN 0718-5049, Santiago de Chile, pp. 227-250

limitándose a señalar el propósito de "llevar a cabo los cambios de fondo que la situación nacional exige sobre la base del traspaso del poder, de los antiguos grupos dominantes a los trabajadores, al campesinado y sectores progresistas de las capas medias de la ciudad y del campo" (1970: 12). Se consideraba necesaria la "toma en sus manos" (Ibíd.) del poder por parte del pueblo, pero para ello se preveían únicamente las formas y los espacios definidos por el Gobierno, dentro de los cauces legales. De esa manera, la toma del poder consistía esencialmente en la incorporación progresiva de los sectores populares a los distintos niveles de la administración del Estado, empezando por la entrada a la gestión de las empresas del Área de Propiedad Social (APS), es decir, del sector nacionalizado de la economía, constituido a partir de la recuperación de empresas estratégicas del gran capital monopólico, extranjero y nacional; y en su participación activa en la vida política y social del país a través de organizaciones sindicales, cooperativas y Juntas de Vecinos. ${ }^{8}$ Es decir, el proyecto político de la UP buscaba alterar las relaciones de poder pero "actuando desde el estado sobre la sociedad" (Garcés 2004). Es por eso que "los sectores populares aparecen como meros espectadores y sectores de apoyo del proceso" (Harnecker 2003), pero no como actores del mismo. Con todo, a medida que se desarrollaban las contradicciones que contenía la UP y su proyecto -cuya singularidad consistía, en parte, en pretender superar "la dicotomía reforma/revolución" (Álvarez 2010: 237)-, los sectores populares radicalizaron las formas de acción previstas y ensayaron modos efectivos de poder popular que tendían a superar la tradicional división entre gobernados y gobernantes: se trató de los cordones industriales y de los comandos comunales. 9 El Pliego del Pueblo, dado a conocer en octubre de 1972, desarrollaba y concretaba las propuestas de poder popular apenas esbozadas en el programa de gobierno de la UP, buscando establecer otra forma de relación con las instituciones:

Nadie tiene derecho y menos aún en nuestro nombre, a actuar sin consultarnos. Ningún problema es tan complicado ni urgente como para que no pueda ser entendido y discutido por nosotros. Ningún funcionario puede olvidar que su primera responsabilidad es con el pueblo y que está por lo tanto obligado a someterse a su control organizado (1973: 230-231).

\footnotetext{
${ }^{7}$ Lo destacado en cursivas es mío.

${ }^{8}$ Más adelante también por intermedio de las Juntas de Abastecimiento y Control de precios (JAP), creadas para establecer el control popular de la distribución de alimentos, constituyendo un contrapeso a la estrategia de acaparamiento y desabastecimiento implementada por la derecha.

${ }^{9}$ Los cordones industriales consistieron en la organización y articulación de los trabajadores de un sector de industrias para tomar el control de la producción en sus manos y hacer frente así, de manera directa, a los problemas derivados del boicot empresarial y del desabastecimiento intencional. Los comandos comunales fueron órganos de coordinación y toma de decisiones de las distintas organizaciones populares (de obreros, campesinos, pobladores, estudiantes, profesionales y técnicos) presentes en una comuna, destinadas a garantizar el abastecimiento, la seguridad y el transporte, entre otros.
} 
La creación de los cordones industriales se engarza con la añeja tradición de acción directa de una parte del movimiento popular chileno -expresada, por ejemplo, en la creación de mancomunales y sociedades de resistencia entre fines del siglo XIX y principios del $\mathrm{XX}-\mathrm{y}$, más recientemente, con la práctica de la toma -ocupación de sitios, de fundos, de universidades- que los sectores populares habían venido desplegando al menos desde finales de los cincuenta y que se había intensificado a partir de 1970: así, en 1971 se registraron cerca de mil trecientas tomas de tierra, mientras que en 1967 se habían contabilizado nueve (Marín 1973: 59) ${ }^{10}$; por otra parte, a principios de 1973 había unas 250 empresas incorporadas a la APS, por la presión de los trabajadores, frente a las 91 consideradas originalmente por la UP (Cavallo y otros 2013: 32).

La autoorganización de los trabajadores desafiaba, en la práctica, el control obrero ejercido por la Central Única de Trabajadores (CUT) $;^{11} \mathrm{y}$, en un primer momento, los cordones industriales recibieron la desaprobación del Gobierno, especialmente del Partido Comunista (PC), porque implicaban una suerte de "paralelismo" sindical. En efecto, su aparición "significó la crisis de los organismos de mediación y dirección históricos del movimiento obrero, es decir, la CUT y los partidos trabajadores" (Gaudichaud 2004: 35). De hecho, su surgimiento, y más tarde el de los comandos comunales, alentó la discusión acerca del "poder dual". Especialmente para el Movimiento de Izquierda Revolucionaria (MIR), la conformación de estas instancias de control obrero-popular estaba en la base de la creación de un poder alternativo al del Estado burgués - del que, en ocasiones, se excluía al Gobierno, que pese a sus contradicciones era reconocido como "nuestro" Gobierno (Illanes 2002: 161)-. Esta posición contradecía la "revolución dentro de la legalidad" impulsada por la UP y la concepción misma de "gobierno popular" según la cual "el pueblo será el que gobernará directamente, sin intermediarios", como había dicho Allende (citado en Álvarez 2010: 233).

Frente a las dificultades del Gobierno para llevar a cabo su programa, las contradicciones internas, el excesivo centralismo, la rigidez de los partidos políticos y la burocratización de la CUT, una parte significativa de los sectores populares dieron forma a una instancia propia y directa, con predominio de mecanismos democráticos, para hacer frente a los problemas que los acuciaban. En los hechos estaban resolviendo el dilema que enredaba y maniataba a la UP: al asumir por sí mismos la construcción del poder popular, los trabajadores estaban "en proceso de creación del instrumento colectivo que permite conducir las amplias masas del país" (Santos 1973: 4). Sin embargo, esa solución pasaba necesariamente por desconocer la Constitución liberal de 1925 y sobrepasar la institucionalidad burguesa emanada de ella. Y, efectivamente, "el propio proyecto de 'transición pacífica' de la Unidad Popular se vio 'desbordado' por

\footnotetext{
${ }^{10}$ También se incrementó significativamente, aunque en menor proporción, el número de huelgas: de setecientas en 1967 a dos mil en 1971 (Marín 1973: 59).

${ }^{11} \mathrm{Y}$ el propio modelo sindical diseñado en el Código del Trabajo de 1931, que restringía la organización obrera por rama de producción o profesión y separaba políticamente a los trabajadores ocupados de los desocupados.
} 
la dinámica de movilización que alcanzaron diversos grupos y movimientos sociales de base" (Garcés 2004). Esos desbordes fueron considerados "inaceptables" por el Gobierno (Gaudichaud 2004: 9).

Sin embargo, la acción de los cordones industriales fue definitoria en la crisis de octubre de 1972, cuando los dueños de camiones se declararon en paro, agravando los ya apremiantes problemas de desabastecimiento y procurando el colapso de la economía. En esa ocasión, los trabajadores tomaron la iniciativa frente al Gobierno y los partidos políticos, que se mostraron vacilantes, y organizados en sus lugares de trabajo se hicieron cargo de las tareas de producción y distribución, evitando la paralización del país. A poco andar, la potencia creadora de los cordones industriales fue reconocida tanto por el PC y la CUT, como por el propio Allende (1973a: 8): "La dinámica social lleva a crear los centros de poder de los trabajadores; lo que se ha llamado el Poder Popular". Eso sí, siempre y cuando estuviera "vinculado este poder popular al Gobierno, sin que sea antagónico con el régimen institucional" (Allende 1973b: 11). En definitiva, la exigencia era, a la vieja usanza, castrar la radicalidad y potencialidad popular para fijarla a los amarres institucionales que el Gobierno había acordado respetar. Sólo así se entienden las medidas destinadas a forzar la restitución de las empresas tomadas por los trabajadores a sus dueños o la ley de control de $\operatorname{armas}^{12}$ que, en los hechos, permitía el allanamiento y cerco de las industrias más combativas mucho antes del golpe de Estado. De esa manera, el poder popular quedaba "prisionero de los límites de la política parlamentaria y estatal" (Löwy 2004: 12).

La UP, boicoteada por la centro-derecha y por los intereses capitalistas extranjeros desde su nacimiento, fue entrampándose en sus propias definiciones de principios: el respeto a una institucionalidad y a una legalidad que conspiraba contra las transformaciones radicales que buscaba realizar. Las dificultades programáticas agudizaron las diferencias internas, evidenciando tensiones entre los partidos políticos, que fueron resumidas en las consignas "consolidar para avanzar" -hegemonizada por el PC y el propio presidente- y "avanzar sin transar" -defendida, principalmente, por un sector significativo del Partido Socialista (PS) y por el MIR, éste último desde fuera de la coalición gobernante-. Pero más que de dos bloques homogéneos, asistimos a contradicciones internas y radicalizaciones en casi todos los partidos políticos de la UP, con excepción del PC. Y frente a las diferencias manifestadas a nivel de las estructuras partidarias destaca la relativa "ausencia de sectarismo que se presenta en las bases" (Santos 1973: 4), al mostrarse los trabajadores, en sus espacios de trabajo y de vida, más dispuestos a la colaboración y a la resolución de los problemas concretos que a las disputas ideológicas. En ese sentido, los cordones industriales ejemplifican cómo "ciertas fracciones del movimiento social se encontraron a menudo en desfase con sus direcciones políticas históricas" (Gaudichaud 2004: 16), traduciéndose ello en una tensión entre su identidad de "clase" y su pertinencia partidaria (Ibíd: 47; Garcés 2004). No obstante, a pesar de sus discrepancias también con respecto al lugar teórico y práctico que debían ocupar los cordones industriales y los comandos comunales, los

${ }^{12}$ Ley 17.798, promulgada en octubre de 1972. 
partidos de la UP habrían manifestado una tendencia unánime a "canalizar" esas formas de organización y control obrero y popular (Gaudichaud 2004: 48).

Con todo, es imprescindible señalar que los partidos políticos tuvieron un peso significativo en la creación y organización de los cordones industriales y los comandos comunales; los historiadores que han estudiado este periodo han puesto de manifiesto que el PS y el MAPU (Movimiento de Acción Popular Unitaria) tenían mayor ascendiente en los primeros, mientras que la influencia del MIR -considerado su "padre ideológico" (Leiva 2004) - era significativa en los segundos (Winn 2004: 322). No obstante, la naturaleza y la dinámica de estas formas de autoorganización excedían las definiciones partidistas y controvertían el modo de relación histórico entre movimiento social y partido político, al diluir la diferencia entre ambas configuraciones y asumir de manera directa y unida la gestión de la sociedad. Por eso, cordones industriales y comandos comunales fueron embriones de una sociedad comunista; contenían el germen de un tipo de relaciones sociales distinto del capitalista, basado en la participación activa de toda la comunidad para decidir colectivamente sobre su destino. Todo ello a pesar de las contradicciones que asimismo contenían y que se refieren, a nuestro juicio, precisamente a la débil consideración teórica de la necesidad de superar la escisión entre lo social y lo político, como queda de manifiesto en la siguiente declaración, extraída de la carta que la Coordinadora Provincial de cordones industriales dirigiera a Allende, pocos días antes del golpe de Estado:

Por lo tanto le exigimos a usted, compañero Presidente, que se ponga a la cabeza de este verdadero Ejército sin armas, pero poderoso en cuanto a conciencia, decisión, que los partidos proletarios pongan de lado sus divergencias y se conviertan en verdadera vanguardia de esta masa organizada, pero sin dirección (2004: 457).

Así pues, si bien es cierto que en los cordones industriales y comandos comunales se anudan las luchas sociales de trabajadores, pobladores, estudiantes, etc. en sus lugares de trabajo y de residencia, con la lucha de los partidos que se reivindicaban su instrumento político, es decir, la unidad de lo social y lo político, contra la política parlamentaria, de los acuerdos "por arriba", también lo que es que la inercia de la vieja relación de dirección y conducción de la vanguardia sobre la masa impregnaba tanto a los dirigentes políticos como a los militantes sociales. A pesar de las tensiones, es justo decir que aquellas dinámicas de poder popular "expresan un campo de conflicto y búsqueda de nuevas formas de hacer política desde los movimientos sociales populares" (Garcés 2004). Esa búsqueda estaba orientada a la superación de las formas exclusivamente "representativas y delegativas de hacer política" (Luis Cruz citado en Gaudichaud 2004: 35) y, por lo tanto, tendía a romper la estricta disociación entre "lo social" y "lo político", como dos campos de acción con lógicas, formas y actores claramente diferenciados. La escisión fue tensada y tendencialmente superada. Lo "amenazante" para los grupos económicamente poderosos y para la élite gobernante era esa radicalidad práctica, y no la capacidad 
militar de ese "Ejército sin armas", por más que la coartada de la derecha fuera la existencia de grupos de choque con entrenamiento paramilitar, dispuestos a instaurar la dictadura del proletariado. Pero el poder popular no tuvo tiempo de desplegarse y fortalecerse; el golpe de Estado barrió con esas experiencias.

\section{La escisión forzada}

Con la Dictadura cívico-militar se cancelaron las instituciones y las formas que hasta ese momento habían constituido la democracia chilena; también se violó el contenido que había inspirado y encarnado las luchas democratizadoras en el pasado: los logros -contradictorios pero progresistas- de participación política, equidad económica y justicia social. Tanto en los hechos -clausura del Congreso, disolución de los partidos políticos de izquierda, de la CUT y de otras organizaciones populares, destrucción de los registros electorales, etc.-, como en el discurso, los militares se encargaron de poner de manifiesto su propósito de despolitizar la sociedad chilena y desideologizarla -al identificar ideología con marxismo-. La derecha -junto con la Democracia Cristiana- instigó y aplaudió el golpe de Estado, y consideró oportuna la prescindencia de los partidos políticos justo cuando "el proyecto democrático alcanzaba su naturaleza y entraba en su fase revolucionaria" (Illanes 2002: 156); y en sintonía con el mandato militar, el Partido Nacional se declaró en "receso político" y, poco después, se autodisolvió (Valdivia 2006: 29-35).

La Dictadura venía, una vez más, a "sacrificar la democracia para salvar el capitalismo" (Vasconi 1991: 47). Pero para ello era necesario formatear la conciencia histórica de los chilenos y dar forma a una nueva sociedad, o de otra manera: "cambiar la mentalidad de los chilenos", como estableció la Declaración de Principios del Gobierno de Chile, de 11 de marzo de 1974. Ése es uno de los primeros documentos oficiales que da cuenta de la pretensión refundadora y totalitaria de la recién inaugurada empresa. Allí está formulada la clave, a nuestro parecer, del diseño institucional ideado por la Dictadura, que a la postre fue acatado y perfeccionado por la Concertación. Esa clave es la "descentralización funcional":

La nueva institucionalidad que hoy se está creando distinguirá entre el poder político y el poder social, separando claramente sus titulares y su forma de ejercicio. El poder político o facultad de decidir en los asuntos de interés general para la nación, constituye propiamente la función de gobernar al país. El poder social, en cambio, debe entenderse como la facultad de los cuerpos medios de la sociedad para desarrollarse con legítima autonomía hacia la obtención de sus fines específicos.

Los militares asumieron la plenitud del "poder político" y no estipularon plazos para devolverlo a los civiles porque, a su parecer, la meta "de reconstruir moral, institucional y materialmente al país, requiere de una acción profunda y prolongada". Con respecto al poder social, se impusieron la tarea de "asegurar la independencia y 
despolitización de todas las sociedades intermedias entre el hombre y el Estado". Con ello se establecía que el "poder político" debía descansar en una élite técnico-militar desgajada de los grupos sociales (bajos y medios); y que las organizaciones sociales (de existir) debían abocarse a asuntos al margen de la política. La escisión entre lo social y lo político, o la política, implicaba también la reducción de la política a lo estatal -por lo demás, una formulación clásica- y, lo que es más novedoso, una concepción no conflictiva de la misma, esto es, se presupone que la actividad política al autonomizarse de la sociedad exorciza la posibilidad del antagonismo entre intereses distintos; así, la política queda restringida a la mejor "administración de lo dado, de lo instituido" (Retamozo 2009: 81) por parte de un "gobierno impersonal" que se arroga la potestad de decidir sobre la procura "del bien común y de la justicia", "por encima de todo grupo particular de cualquier naturaleza, desterrando el juego de las influencias". ${ }^{13}$

Las trasformaciones introducidas por los militares alteraron la forma de articulación de los distintos actores socio-políticos. La persecución y represión de cualquier forma de expresión política, quebró la "columna vertebral" de la sociedad chilena, esto es, la forma clásica de relación entre la sociedad y el Estado -o la política- (Garretón 1987c). De manera más concreta esa relación se había caracterizado, a juicio del sociólogo chileno, por el hecho de que los actores sociales se constituían en estrecha vinculación con la estructura política, que incluía partidos de alcance nacional que representaban de izquierda a derecha el espectro políticoideológico. De esa vinculación dependía el alcance y significación de las organizaciones sociales, hecho que redundaba a su vez en una escasa autonomía y mayor dependencia de las mismas con respecto de los partidos políticos. Todo ello determinaba que "hacer política en Chile consistía en organizar una base social vinculándola a la estructura partidaria y presionar sobre el Estado" (Garretón 1982). Resulta entonces que "el fin de la Unidad Popular es también el fin de un "modo histórico' de 'hacer política"” (Garcés 2004), porque durante la Dictadura, a pesar de los esfuerzos por restaurar la vieja forma de relación entre los movimientos sociales y los partidos políticos, ello no fue posible, como tampoco la instauración de un nuevo modo de vinculación; más bien se profundizó la escisión.

$\mathrm{Si}$ aceptamos que aquélla haya sido la forma prioritaria de constitución de actores socio-políticos durante el período predictatorial, lo cual habría impedido su autonomía, ${ }^{14}$ tanto en sus formas como en sus fines, debemos conceder también que durante la Dictadura la dependencia fue segada de tajo. Al cercenar el "estamento" intermedio (la estructura político-partidaria), que funcionaba como correa de transmisión de los actores sociales hacia el Estado -y viceversa-, la base social quedó descolgada, incapaz ya de dirigirse al Estado por los canales y formas tradicionales,

\footnotetext{
${ }^{13}$ Todas las citas de este párrafo, salvo que se indique lo contrario, provienen de la Declaración de Principios del Gobierno de Chile.

${ }^{14}$ Lo cual no significa que los movimientos sociales estuvieran absolutamente controlados por los partidos políticos, como hemos puesto de manifiesto en el apartado anterior. Por otra parte, la autonomía siempre es relativa, implica una relación de la cual uno no puede abstraerse completamente.
} 
desarticulada y atomizada; y el Estado, en una posición ambigua, dado el poco peso teórico que le otorgaba el modelo neoliberal implementado a partir de $1975^{15} \mathrm{y}$, en contraposición, el gran "poder concentracionario" (Calveiro 2008) y terrorista que desplegó a lo largo de los 17 años que duró la Dictadura. Así, la base social fue sometida a una autonomización forzada y se vio obligada a actuar por sí misma, sin estructuras mediadoras y sin posibilidad de interlocución con el Estado: "Precisamente en las peores condiciones, parecen darse elementos que apuntan a la construcción de actores populares autónomos que si bien inicialmente reproducen en una nueva arena la vinculación político partidista, poco a poco adquieren dinámicas propias" (Garretón 1987c: 10-11). Frente a la tensa y dificultosa independencia que las experiencias de poder popular trataron de cultivar durante la UP, la autonomía de los actores sociales provino de un proceso contrarrevolucionario, de la represión y de la fragmentación social. Por ello Garretón se preguntaba:

¿Se trata de un proceso de organización social transitorio en que predominan los aspectos defensivos de la organización frente a un mundo que se rechaza y la rechaza? ¿Están condenadas a morir cuando lo político reaparezca y en un futuro democrático? (1987c: $11){ }^{16}$

Paradójicamente, la consideración de la mayor autonomía de los actores sociales no suponía atribuirles un carácter político, porque lo político siguió interpretándose, desde esta perspectiva, en un sentido clásico y restringido, como lo partidario y lo estatal, como una esfera específica separada de lo social.

Frente a los movimientos sociales que habían tenido mayor presencia en la sociedad chilena -obrero, campesino y estudiantil- con anterioridad al golpe de Estado, que fueron significativamente afectados por la represión, la reestructuración económica y el reordenamiento jurídico-político implementado por Pinochet, emergieron durante la Dictadura formas de organización y de protesta, sobre todo en las poblaciones marginales, que llamaron la atención de políticos y académicos. Los pobladores crearon y apoyaron un amplio abanico de organizaciones vinculadas con la sobrevivencia, con la defensa de los derechos humanos, con la educación popular, etc. Las organizaciones económicas populares -como se conoce a la variedad de iniciativas populares para enfrentar el desempleo, el hambre, la escasez de vivienda, la enfermedad, el cuidado de los niños, etc.- proliferaron durante la Dictadura como una respuesta propia de los sectores más afectados por la contrarrevolución para hacer frente por sí mismos, de manera autogestionaria, asociativa y democrática, a sus carencias y necesidades concretas. ${ }^{17}$ Experiencias populares que desarrollaron la

\footnotetext{
${ }^{15}$ Que fue contestado, sin embargo, en los hechos, con políticas activas en favor de la reestructuración capitalista. Contrariamente a la imagen de un Estado "arbitro", con poca injerencia, lo que tenemos es un Estado neoliberal, basado en el principio de subsidiaridad.

${ }^{16}$ Lo destacado en cursivas es mío.

${ }^{17}$ Según el economista Luis Razeto, en marzo de 1984 había 702 organizaciones económicas populares catastradas y, en julio de 1985, 1103 (1990: 15).
} 
Mónica Iglesias V., Lo social y lo político en Chile: Itinerario de un desencuentro teórico y práctico / The social and politics in Chile: theoretical and practical disagreement, Revista Izquierdas, número 22, enero 2015, ISSN 0718-5049, Santiago de Chile, pp. 227-250

sabiduría, la cultura y las habilidades de los pobladores. De hecho, algunos autores reconocieron en ellas el germen de relaciones sociales distintas, basadas en la solidaridad (Razeto 1987). Sin embargo, esta opinión fue absolutamente marginal; la sociología hegemónica hizo hincapié en el carácter defensivo, de rechazo (por lo tanto, negativo) de dichas iniciativas y en la ausencia de proyecto político.

De otra parte, las protestas nacionales que estallaron en 1983 y que, con altibajos, se sucedieron hasta 1986, contaron con gran protagonismo de los sectores populares. En estas movilizaciones destacó la participación de los pobladores, cuyas luchas habían gozado de repercusión política y de interés teórico al menos desde los años sesenta (Garcés 2002), pero que no habían sido leídas propiamente en clave de "movimiento social" sino como "sujetos marginales" o, en el mejor de los casos, como una fracción de la clase obrera. ${ }^{18}$ Esa discusión fue abordada en los ochenta y tomó en consideración el potencial democratizador de las protestas y de la movilización social, con vistas a la salida de la Dictadura. En términos generales, la sociología concluyó que las protestas y las formas de organización de los pobladores no constituían movimientos sociales, sino formas desviadas de acción social, caracterizadas, de un lado, por la anomia y el retraimiento y, de otro, por la violencia. ${ }^{19}$ Con ello, la sociología no sólo zanjaba un debate académico sino que negaba legitimidad a las movilizaciones populares regateándoles el carácter político. Cabe recordar que, en aquel momento, se desarrollaba una disputa a nivel de las estructuras partidarias entre una posible salida negociada a la Dictadura (que incluía un acuerdo con los militares y con la derecha política) y una salida insurreccional de la misma, que se apoyaba en el fortalecimiento de las organizaciones sociopolíticas y en el enfrentamiento con la Dictadura. Esa discrepancia se zanjó, en los hechos, a favor de la primera opción.

\footnotetext{
${ }^{18}$ Efectivamente los estudios de principios de los setenta ponen de manifiesto tanto la dificultad de encasillar a los pobladores en un mismo estrato social, dada la heterogeneidad del mundo poblacional, como el predominio obrero entre esos sectores, definidos como marginales (Espinoza 1988: 336-337). En las poblaciones callampa coexistía una proporción significativa de personas formalmente ocupadas en la industria, con otros sectores sin ocupación formal o con trabajos temporales y esporádicos. Esos hallazgos pusieron en entredicho los presupuestos de la teoría de la marginalidad. Con todo, la discusión teórica al respecto fue especialmente intensa por sus implicaciones políticas: entender a los pobladores como parte de la clase obrera, significaba incorporarlos a las directrices del movimiento obrero y de sus representantes sindicales y políticos; en cambio, validar la especificidad de los pobladores suponía otorgarles un estatus político propio y reconocer la diversidad del mundo popular y, por ende, descentrar la lucha política del movimiento obrero en su formulación más cerrada.

${ }^{19}$ Una temprana crítica de este razonamiento puede encontrarse en Salazar (1986). En este sentido, la afirmación de Moulian del epígrafe que encabeza este artículo puede ser matizada: efectivamente la relación entre partido político y movimiento social ha estado atravesada históricamente por tensiones y contradicciones, y la cultura política chilena ha tendido a darle preeminencia a la política entendida como una actividad esencialmente representativa (función que cumplen los partidos); sin embargo, esta misma concepción ha influido en las ciencias sociales y en la manera como se han estudiado los movimientos sociales, redundado en una dificultad para visibilizar y poner en valor las muchas y variadas luchas sociopolíticas que han estado presentes en la historia chilena. Los partidos políticos han tendido a dominar a los movimientos sociales, pero éstos han existido más de lo que suele reconocerse.
} 
Curiosamente se reeditaban las diferencias tácticas que emergieron durante la UP; esta vez se demostraron, además, estratégicas. ${ }^{20}$

\section{La escisión legitimada}

Las "siete modernizaciones"21 anunciadas por Pinochet en 1979 constituían el programa esencial del neoliberalismo que los Chicago Boys buscaban implementar en Chile. En 1980 el dictador hizo aprobar una nueva Constitución que dibujaba la futura institucionalidad política y -aspecto fundamental en ese momento- fijaba los plazos de la entrega del "poder político", que se preveía, en el mejor de los casos, para 1990. La oposición a la Dictadura cuestionó la legitimidad de la carta magna, negando su validez por haberse refrendado en un plebiscito carente de garantías democráticas, mientras imperaba la represión política y la violación sistemática de los derechos humanos. Sin embargo, a poco andar, el itinerario esbozado allí operó como un mapa con el cual una parte de la oposición decidió orientarse. De manera explícita, a partir de 1984, el sector más conservador de la oposición, aquel que había saludado el golpe de Estado, retomó la cercanía con los militares al reconocer la legitimidad de facto de la Constitución (Godoy 1999: 90): "La única ventaja que él [Pinochet] tiene sobre mí es que esa Constitución está rigiendo. Es un hecho, y lo acato" (Aylwin 1984: 10-11). Por eso, el democratacristiano recomendó "eludir deliberadamente el tema de la legitimidad [...] hagamos un esfuerzo en buscar coincidencias para llevar al país a la normalidad democrática" (Ibíd.). Pero lo que se presentaba como una posibilidad de salida del régimen, en realidad era su aceptación.

La fase de institucionalización de la Dictadura, formalizada con aquellas dos iniciativas políticas, acabó con las esperanzas de una pronta retirada de los militares. En el ámbito de las ciencias sociales y políticas, la noción de democracia se constituyó en la preocupación principal y, también, en "un ideal práctico, orientador de las luchas políticas" (Flisfisch 1987: 154). Así, la transición a la democracia adquirió categoría de programa de estudios y, sobre todo, de programa político. En ese contexto, el trabajo de los politólogos Guillermo O’Donnell y Philippe C. Schmitter, Transiciones desde un gobierno autoritario (Buenos Aires, Paidós, 1988), se convirtió en el vademécum de los políticos y científicos sociales chilenos, en la órbita de la renovación socialista y de la Democracia Cristiana. De acuerdo con aquellos autores, la transición se refiere exclusivamente a la democracia política, es decir, al cambio de régimen, dejando pendientes para una etapa posterior los problemas de

\footnotetext{
${ }^{20}$ Resulta ilustrativa, a este respecto, la dicotomía que construye Joan Garcés para explicar las diferencias tácticas que se habrían expresado en la UP: la "vía insurreccional" versus la "vía política". A pesar de reconocer lo problemático de la formulación, identifica la primera con la construcción del poder popular, en cuanto configuración de un poder dual, y la "política" como la transformación desde -y con las herramientas- de las propias instituciones del Estado (1974, cap. 7).

${ }^{21}$ Se trata de reformas que afectaban a siete áreas básicas: política laboral, seguridad social, educación, salud, descentralización regional, agricultura y aparato judicial.
} 
Mónica Iglesias V., Lo social y lo político en Chile: Itinerario de un desencuentro teórico y práctico / The social and politics in Chile: theoretical and practical disagreement, Revista Izquierdas, número 22, enero 2015, ISSN 0718-5049, Santiago de Chile, pp. 227-250

democratización social, referidos a los "cambios sociales tendientes a la mayor igualdad de oportunidades y a la participación social" (Garretón 1993: 3), que se verifican durante la "consolidación democrática" (Ibíd.: 4). Algo así como una democratización en dos pasos: primero la restauración del sistema político liberal, después la transformación socioeconómica y del propio marco institucional dictatorial, desde su interior. O’Donnell reconocerá, años después, el sesgo formal de su enfoque, excusándose en que "en esa época (segundo quinquenio del '80) el logro de una democracia política aparecía tan inmensamente importante que quisimos concentrarnos en los factores y procesos políticos y sociales que podían conducir con la mayor celeridad a ella" (2004: 18). Un régimen democrático, así entendido, nada tiene que ver con el modelo económico y social; de ahí que el "padre" de la transitología afirme:

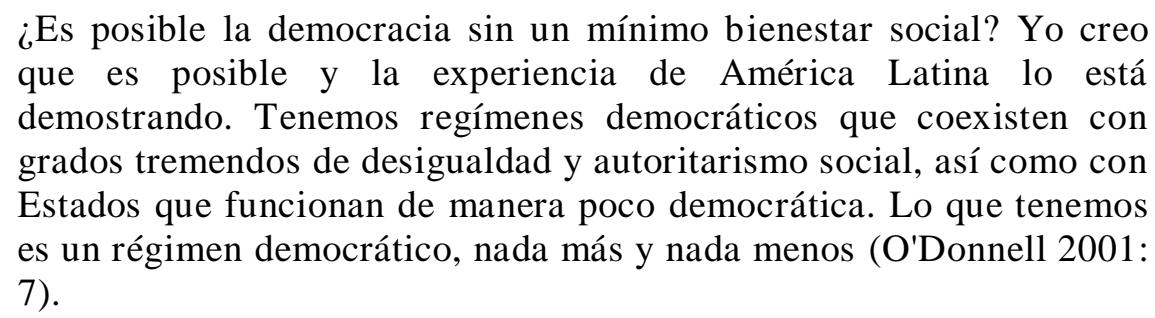

Desde esta perspectiva, los transitólogos chilenos debieron definir cuáles eran los problemas fundamentales que la oposición debía resolver, a saber: qué actores políticos -o no políticos, pero con un rol político en esa coyuntura- iban a jugar un papel relevante en la transición; qué modalidades de acción política debían privilegiar, cuáles subordinar y cuáles descartar, y qué acontecimientos constituirían los hitos políticos que marcaban el camino de la transición. Con base en lo anterior, concluyeron que los partidos políticos, las fuerzas armadas y la Iglesia serían los actores privilegiados; que debían combinar la movilización social con la negociación política, con fuerte preeminencia de la segunda; y que las fechas que establecía la propia Constitución pinochetista definirían la hoja de ruta. En definitiva: "Una salida 'a la chilena', un pacto en las alturas, sin pueblo, para retornar y hacer posible el viejo 'Estado en forma' y una democracia restringida o, mejor aún, con realismo político" (Garcés 2012: 23).

La "sociología transicional" 22 se interesó en las movilizaciones sociopolíticas desde el punto de vista de su capacidad para contribuir a la recuperación democrática. De acuerdo con las premisas referidas más arriba, "no cualquier movilización en cualquier momento es funcional a un proceso de transición política" (Garretón 1986a:

22 La expresión hace alusión, precisamente, a los sociólogos que se dedicaron a la investigación/construcción de la transición pactada. Se trata de una sociología con un fuerte predominio de la ciencia política - preocupada, como hemos señalado anteriormente, por el cambio de régimen-. Entre los transitólogos más destacados se encuentran José Joaquín Brunner, Ángel Flisfisch, Enrique Correa, Eugenio Tironi y Manuel Antonio Garretón. Coincidimos con Tomás Moulian en que “M. A. Garretón, el menos oído, es el más importante desde el punto de vista del análisis, porque no se queda en la pura transición" (2008: 163). 
7). De ahí que fuera necesario realzar unas y anatemizar otras. Entre las luchas que no se consideraban convenientes se encontraban aquellas que se insertan en procesos defensivos o de autoafirmación de identidad, las que se ubican en la dimensión revolucionaria y las que apuntan a la democratización global, según las propias caracterizaciones de Garretón. Cabe hacer notar que la mayoría de las movilizaciones y protestas que habían tenido lugar entraban dentro de alguna de estas categorías:

Tanto el largo ciclo de las protestas que, pese a haber despertado y reorganizado la sociedad, terminó desgastado, como las movilizaciones de 1986, acusaron el mismo defecto: no se insertaron en un diseño y propuesta de cambio y transición coherente y unitario de las fuerzas políticas que la dirigían (Garretón 1987a: 8).

Frente a esa lógica de acción, Garretón contraponía otra: "La instrumental, racional, orientada hacia el uso de la institucionalidad y la concertación en torno a metas precisas" (1987d: 17). Coexistían, pues, dos orientaciones disociadas, encarnadas por actores distintos, que eran la expresión palmaria de la ruptura de la matriz socio-política clásica: una propiamente racional; la otra, "simbólico-expresiva". Y agregaba: "La primera queda entregada a cúpulas y organizaciones políticas que no logran convocar movilizaciones amplias. La segunda a sectores motivados y activados que no saben cómo transformar una fuerza social en fuerza política" (Ibíd.: 17-18). ${ }^{23}$ Pero lo cierto es que "las negociaciones y concertaciones en el nivel de las cúpulas y de las élites tienden a reemplazar las movilizaciones sociales durante la transición democrática y los procesos de consolidación" (Garretón 1996). Ante esa realidad, una de las preocupaciones del sociólogo era, precisamente, "evitar la polarización y el desborde institucional" que podían propiciar los grupos no funcionales a la transición política poniendo en aprietos los pactos entre élites (Garretón 1986a: 17). ${ }^{24}$

En efecto, esta diversidad de oposiciones, que se relaciona con la multidimensionalidad de las luchas contra la Dictadura, planteaba un difícil desafío a los grupos de la oposición que entendían la transición en un sentido exclusivamente formal, pues según el sociólogo "en parte, la aceleración de un proceso de transición depende de la capacidad de los componentes de la oposición de aislar y priorizar la dimensión de transición política en relación a las otras" (Garretón 1986a: 2-3). ${ }^{25}$ Ese proceso se precipitó, ciertamente, después del fracaso de la "Operación Siglo XX", el atentado contra Pinochet protagonizado por el Frente Patriótico Manuel Rodríguez, tras el cual Garretón se apresuró a señalar: "Es irreal pensar que podrá haber una transición por la vía de la sublevación o insurrección” (1986b), "porque no hay otra salida que no sea con negociación, impuesta, forzada, pero negociación al fin” (1987a: 12). Además

\footnotetext{
${ }^{23}$ Lo destacado en cursivas es mío.

${ }^{24}$ Se actualizaba, así, el problema de los "desbordes institucionales" y de la "conducción política". Las fallas en la conducción política por parte de la Unidad Popular, es una de las hipótesis aceptadas tanto por la derecha como por los partidos de ese conglomerado -desde una perspectiva partidista y elitistasobre la responsabilidad que le habría cabido a ésta en el advenimiento del golpe de Estado.

${ }^{25}$ Lo destacado en cursivas es mío.
} 
de las organizaciones político-militares, otros sectores planteaban dificultades a la plena aceptación de la negociación, por ejemplo, aquellos que seguían insistiendo "a menudo en temas del futuro que dicen relación con los modelos económicos o sociales, que sólo empantanan un acuerdo que debe excluir todo contenido que no sea el cómo se resuelve el problema de quién y cómo gobierna la sociedad" (Ibíd.: 13). En ese sentido, las acciones de los pobladores ${ }^{26}$ eran vistas, por la transitología, incluso como una amenaza para la futura democracia:

Los pobladores, en efecto, son vistos como un foco de demandas económico-sociales que pueden arrastrar en cualquier momento a estallidos de violencia, lo que desde un punto de vista democrático sería doblemente disfuncional: de una parte, la "violencia de los pobladores" estimula en la sociedad las demandas autoritarias, lo que bloquea la transición; y de otra, está la posibilidad de que ella se haga incontenible con el fin del autoritarismo, lo que va en contra de la consolidación del nuevo régimen democrático. "Qué hacer" con los pobladores, por lo tanto, se ha transformado en una de las grandes preocupaciones de la clase política chilena (Tironi 1990: 181). ${ }^{27}$

Pero excluir, desdeñar y subordinar a los movimientos sociales no significaba prescindir completamente de ellos, sino incorporarlos de manera dependiente $y$ subordinada a la estrategia política diseñada por las cúpulas políticas y los intelectuales asociados. Para los teóricos de la transición, "la relación entre movilización popular y negociación política adquiere un carácter crucial y definitorio en toda estrategia opositora" (Garretón 1987b: 9). La negociación con los militares podría realizarse desde una mejor posición si había detrás un fuerte movimiento social que presionara y amenazara incluso con radicalizar la protesta, pero que fuera en última instancia controlable por los dirigentes políticos. El reto entonces estribaba en saber "combinar los elementos de movilización y presión social, negociación y concertación y presión de instancias mediadoras o arbitrales" (Garretón 1986a: 5). Y es que, a su juicio, sólo esa combinación es capaz de producir un fenómeno de transición política. Para ello, las movilizaciones y protestas sociales populares son importantes, igual que otras "figuras" como la descomposición interna del régimen o la intervención de actores mediadores por encima o por fuera de la Dictadura y de la oposición, como bien pueden ser la Iglesia u organizaciones internacionales. Pero las movilizaciones por sí mismas no constituyen una estrategia de transición, pueden coadyuvar a una vía insurreccional, o a una negociada, en cuyo caso requerirán de la conducción política.

La condición que sobresale es la escisión esencial que se produce entre los dos tipos de procesos -el de movilización y el de negociación/concertación- y los grupos que los llevan a cabo, lo que redunda en que los sectores que se movilizaron en la lucha contra la Dictadura fueran a la postre subordinados a los tiempos y prioridades

\footnotetext{
${ }^{26}$ Sobre el protagonismo de los pobladores en la lucha antidictatorial ver: Iglesias (2011).

${ }^{27}$ Lo destacado en cursivas es mío.
} 
Mónica Iglesias V., Lo social y lo político en Chile: Itinerario de un desencuentro teórico y práctico / The social and politics in Chile: theoretical and practical disagreement, Revista Izquierdas, número 22, enero 2015, ISSN 0718-5049, Santiago de Chile, pp. 227-250

definidos por las cúpulas políticas. La manera de justificar este disciplinamiento de los movimientos sociales es apelando a un imperativo táctico: "El éxito de la unidad y la predominancia del factor político-partidario, tiene como contraparte, quizás inevitable, el decaimiento del movimiento propiamente social, lo cual también tendrá efectos en el carácter del primer gobierno democrático" (Garretón 1993: 11).

El argumento transitológico se sustenta nuevamente en la escisión entre lo social y lo político, porque las movilizaciones sociales -de tipo expresivo-simbólico o de corte instrumental-reivindicativo- son concebidas como carentes de proyecto, y en cambio la "movilización propiamente política" (Garretón 1986a: 7) se presenta como la única que "se guía por metas y métodos referidos al término y cambio del régimen militar" (Ibíd.). Por lo tanto, es ésta la única que tiene una estrategia, a la cual se deben sujetar las otras. Lo social carece de dimensión política; por política se entiende la negociación cupular; la política debe disciplinar lo social.

En relación al orden social, el fin de la fase de movilización social, marcado por el fracaso del intento populista de la 'Demanda de Chile" formulada por la Asamblea de la Civilidad, radicó definitivamente en los partidos políticos la conducción de la oposición. Las organizaciones sociales reconocieron la primacía de lo político, pasando a apoyar la nueva estrategia político-electoral de naturaleza eminentemente conciliadora en el plano social (Boeninger 1997: 370).

Una vez acatado el derrotero electoral propuesto por Pinochet, el plebiscito de 1988 se presentaba como la fecha clave para la oposición, y ése era "un escenario apto para los partidos, no para los movimientos sociales" (Tironi 1987: 17), así pues, era necesario "reconocer la transición como un momento político, que requiere de una (momentánea) desarticulación entre lo político y lo social" (ibíd.). Esa desarticulación no fue momentánea; como hemos tratado de reseñar hasta aquí, forma parte del modelo de sociedad diseñado por la dictadura, que acató la Concertación de Partidos por la Democracia. ${ }^{28}$ De esa manera, estamos ante "una izquierda que ha neoliberalizado la sociedad chilena y al neoliberalizarla en democracia le ha aumentado la legitimidad al neoliberalismo" (Moulian 2008: 173); y más aún, ha dotado de legitimidad teórica y

${ }^{28}$ Cabe señalar que la coalición es, sustancialmente, una concertación político-partidista, aunque inicialmente también se sustentara en organizaciones sociales y amplias mayorías ciudadanas. En este sentido, la exclusión del PC de la Concertación fue advertida como un riesgo de desestabilización, en la medida en que "plantea el problema del posible resurgimiento de las tendencias más radicalizadas y exige repensar las formas de canalizar o integrar lo que se ha llamado 'cultura comunista', claramente minoritaria, pero aún significativa" (Garretón 1990: 14). Desde esta perspectiva, la reciente incorporación del PC a la Nueva Mayoría puede ser leída como el cierre del compromiso de la cúpula política-partidista con la transición pactada; mantenerlo fuera de los acuerdos de Gobierno supone marginar a un actor que puede desde la lucha socio-política dificultar la gobernabilidad. Por eso, para los transitólogos, "el regreso pleno de los comunistas a la arena democrática no es una amenaza. Al revés, es un signo positivo para una sociedad que necesita institucionalizar sus conflictos" (Tironi 2013). 
práctica, la escisión entre lo social y lo político, y la subordinación de lo primero a lo segundo. Los propios sociólogos que legitimaron la escisión lo han reconocido:

Ello confiere a los actores políticos, en el gobierno y la oposición, roles claves en la acción social subordinando, de esta manera, los principios de acción de otros actores a su propia lógica. A su vez, las tareas relacionadas con el proceso de consolidación privilegiaron, al comienzo, las necesidades y requerimientos del ajuste y estabilidad económicos desincentivando, así, la acción colectiva que se pensaba ponía en riesgo tales procesos. Como resultado, se produce un cierto grado de desarticulación y desactivación de los movimientos sociales (Garretón 1996).

Frente a posiciones "idealistas" o "éticas", la transitología propuso optar por el pragmatismo porque "en política, a partir de la gran visión de lo que se quiere, hay que transformar la hipótesis de probabilidad real de lo que se desea en diseño y compromiso efectivo de acción, sin concesiones a lo que uno hubiera deseado en abstracto" (Garretón 1987a: 2). Paradójicamente, el sociólogo -sin que mediara acto de contrición- habría acusado, recientemente, el predominio en la Concertación de un alma:

[...] pragmática, que expresaba la postura de no entrar en las discusiones, de evitar una desestabilización económica, de tomar las correlaciones de fuerzas como algo dado, de emprender todas las transformaciones posibles pero no avanzar sin negociar con la derecha, de no alentar movilizaciones (Garretón 2012). ${ }^{29}$

En definitiva, en la década de los ochenta, se ensayaron dos alternativas para poner fin al régimen dictatorial: una fomentaba la participación popular y buscaba una salida que permitiera no sólo acabar con un modelo político tiránico sino también revertir las transformaciones económicas implementadas desde 1973; el otro apostaba por una negociación con los militares y con la derecha política, que garantizara el traspaso del Gobierno de manera ordenada, dejando intactos los aspectos económico y social, sometiéndose a los plazos y formas fijados por la Constitución de 1980, para lo cual debía someter y canalizar las protestas de los sectores populares. Por eso, "la transición se hace sin sujeto popular" (Baño 2013). Esta opción, que se conoce como transición política, legitimó la escisión entre lo social y lo político.

\section{Consideraciones finales}

Cuando la Dictadura apenas insinuaba la magnitud de la contrarrevolución que se proponía llevar a cabo, Ruy Mauro Marini advirtió que la justificación ideológica de

${ }^{29}$ Lo destacado en cursivas es mío. 
estos regímenes militares terroristas "al revés de la que caracterizó al fascismo, no es el rechazo a la democracia representativa, sino la creación de condiciones para que ésta opere con cierta estabilidad" (Marini 1977: 4). La historia confirmó, lamentablemente, la apreciación del sociólogo brasileño: la democracia política que retornó en los noventa se convirtió en la garantía de la gobernabilidad, ese eufemismo de la dominación.

La magnitud de la transformación socio-económica que la reacción cívicomilitar implementó no fue suficientemente considerada por un sector de la oposición. No se advirtió, tampoco, que el rediseño institucional de la Dictadura, sobre el que supuestamente se pretendía actuar a posteriori, suponía una construcción esencialmente distinta de la democracia que había operado con anterioridad al golpe de Estado. La "democracia” recuperada estaba blindaba para "que 'nunca más' se pretenda, en Chile, poner en práctica un proyecto político de la naturaleza y alcances del representado por Unidad Popular", según lo formulara diáfanamente el Ejército de Chile (2004). De ahí que no sea correcto hablar de "enclaves autoritarios", como si se tratara de reductos autoritarios transpuestos en una estructura democrática (Moulian 1997: 54). Y uno de los elementos cardinales, a nuestro parecer, de la "normalidad democrática" que ansiaba Aylwin, es la escisión entre lo social y lo político, que implica además, la subordinación del movimiento social al partido político o, mejor aún, su prescindencia, y la elitización y fetichización de la política, esto es, la autonomización aparente de la esfera política del mundo social, redundando en realidad en beneficio de los grupos económicamente poderosos. Ése era el modelo "ideal" imaginado en la Declaración de Principios del Gobierno de Chile, que la "sociología transicional" contribuyó a legitimar: la transición a la democracia es, en ese sentido, su mejor producto; y el modelo de sociedad resultante, un engendro de aquella teoría, constituyendo un caso paradigmático de performatividad de la ciencia.

La escisión entre la política y lo social no puede ser sino la fetichización de lo político, esto es, la ruptura y separación entre el fundamento de algo y ese algo, que adquiere entonces "vida propia" y aparenta tener por sí mismo unas cualidades que no obtiene sino de aquello que constituye su raíz. Así, la política aparece como una esfera distinta, escindida, autónoma del mundo social. A su vez, ello implica que el medio se convirtió en fin. La política, en cuanto método y organización -dimensión importante pero reducida-, dio pie a una estructura burocrática tan compleja y extendida que desarrolló lógicas de profesionalización, tecnificación y especialización, que se autoreproducen y producen a los "políticos profesionales"; ésos cuya existencia depende de su ubicación en alguno de los múltiples cargos vinculados a la vía electoral. Una vez dentro de la estructura política la permanencia y ascenso exige gestionar -no modificar- las dinámicas administrativo-burocráticas.

Con ello no pretendemos sostener que con la transición a la democracia no cambió nada. Efectivamente, la coyuntura de 1989/1990 constituye, sin lugar a dudas, un quiebre del régimen político: de una Dictadura se transitó a un régimen político distinto, a una "democracia política". Dentro de una misma fase económica -patrón de acumulación capitalista neoliberal- es posible diferenciar dos períodos a nivel de la 
estructura política. De ahí que la transición política consistiera en "una transición de la dictadura neoliberal a la democracia neoliberal" (Salazar 2007: 26). Así las cosas no hay contradicción entre capitalismo y democracia; de hecho "el capitalismo chileno ya se ha reconciliado con ella" (Tironi 1999: 80). Y la "esfera política" aparece guardando una suerte de independencia de los actores sociales, pero ésta es una imagen distorsionada, porque sólo en parte la política es "autónoma": se ha independizado de los proyectos populares de transformación revolucionaria (e incluso reformista) de la sociedad, no así de los de las élites económicas (Ruiz 2007). El divorcio de la política respecto de lo social-popular esconde su matrimonio de conveniencia con lo socialelitista. En este sentido, la imagen deformada de la autonomización de la política se asemeja a la pretensión de neutralidad atribuida por el liberalismo político al Estado.

Pero, en último término, esta fetichización de "lo político" respecto de "lo social", y su escisión como "la política", no puede deberse sino a la propia escisión social. La vía para su superación es precisamente la reunificación de los actores que producen y reproducen la vida, dotándose de mecanismos de democracia participativa, para controlar en todo momento las condiciones de su existencia. Los partidos políticos reformistas y revolucionarios tradicionalmente procuraron la superación de la escisión entre lo social y la política desde arriba hacia abajo, desde el Estado (sede de la política) hacia la sociedad, para producir una desconcentración del poder, una autodisolución, o una socialización de la política. La vía se ha mostrado históricamente infructuosa. La otra ruta nace desde abajo, propugna la politización de lo social, y fue formulada históricamente como "poder popular".

Recibido: 23 agosto 2014

Aceptado: 17 diciembre 2014

\section{Bibliografía}

Allende, Salvador. "Palabras del Presidente de la República, compañero Salvador Allende Gossens, pronunciadas en la clausura del primer Congreso del Partido Federado de la Unidad Popular". 24 de junio de 1973a, <www.salvadorallende.c1/Discursos/1973/24_junio_1973.pdf>.

- "Palabras pronunciadas por el Presidente de la República, compañero Salvador Allende Gossens, en la sala de plenarios del edificio de la cultura Gabriela Mistral, con motivo del plenario de federaciones, convocado por la Central 
Única de Trabajadores". 25 de julio de 1973b <www.socialismochileno.org/allende/1973/25_julio_1973.pdf >.

Álvarez, Rolando. "La Unidad Popular y las elecciones presidenciales de 1970 en Chile: la batalla electoral como vía revolucionaria." OSAL 28 (2010): 219-239.

Aylwin, Patricio. Hoy 367 (1984) del $1^{\circ}$ al 7 de agosto.

Baño, Rodrigo. Lo social y lo político, un dilema clave del movimiento popular. Santiago: Flacso, 1985.

—. "El golpe a la igualdad: cuarenta años después." Anales de la Universidad de Chile, (2013): 43-57.

Boeninger, Edgardo. Democracia en Chile. Lecciones para la gobernabilidad. Santiago: Editorial Andrés Bello, 1997.

Calveiro, Pilar. Poder y desaparición: los campos de concentración en Argentina. Buenos Aires: Colihue, 2008.

Cárdenas, Juan Pablo. "Los Riesgos de la Apatía." Análisis 392 (1991): 3.

Carmona, Ernesto. Los dueños de Chile. Santiago: La Huella, 2002.

Cavallo, Ascanio, et al. "Especial: Los 22 días que sacudieron a Chile." El Semanal/La Tercera, 8 de septiembre de 2013.

Coordinadora Provincial de Cordones Industriales, Comando Provincial de Abastecimiento Directo y Frente Único de Trabajadores en Conflicto. "Carta de la Coordinadora de Cordones al presidente Salvador Allende (5 de septiembre de 1973)." Poder Popular y Cordones Industriales. Testimonios sobre el movimiento popular urbano, 1970-1973, ed. Frack Gaudichaud. Santiago: LOM Ediciones, 2004: 453-459.

De la Maza, Gonzalo (1999), "Los movimientos sociales en la democratización de Chile." El modelo chileno. Democracia y desarrollo en los noventa, ed. Paul W. Drake e Iván Jaksic. Santiago: LOM Ediciones, 1999.

De la Maza, Gonzalo y Mario Garcés. La explosión de la mayorías. Protesta Nacional 1983-1984. Santiago: ECO, 1985.

"El Pliego del Pueblo." Marxismo y Revolución 1, julio-septiembre 1973: 229-240.

Ejército de Chile. "Respuesta del Ejército de Chile al Informe Rettig." Documentos de La Nación, 18 de noviembre de 2004.

Espinoza, Vicente. "Reivindicación, conflicto y valores en los movimientos sociales de la segunda mitad del siglo XX." Memoria para un nuevo siglo. Chile, miradas a la segunda mitad del siglo XX" ed. Mario Garcés y otros. Santiago: LOM Ediciones, 2000.

—. Para una historia de los pobres de la ciudad. Santiago: Ediciones SUR, 1988. 
Flisfisch, Ángel. La política como compromiso democrático. Santiago: Flacso, 1987.

Garcés, Joan E. El Estado y los problemas tácticos en el gobierno de Allende. México:Siglo XXI, 1974

Garcés, Mario. Tomando su sitio. El movimiento de pobladores de Santiago, 19571970. Santiago: LOM Ediciones, 2002.

—. "Los movimientos sociales populares y la izquierda chilena en la Unidad Popular y su respuesta frente al golpe de Estado de septiembre de 1973.” 2004. $<$ www.archivochile.com/Ideas_Autores/garcesm/garcesm0004.pdf $>$.

- El despertar de la sociedad. Los movimientos sociales en América Latina y Chile. Santiago: LOM Ediciones, 2012.

Garretón, Manuel Antonio. "La política ayer y hoy." Chantilly I - Chile 80 Movimientos, $\quad$ Escenarios $\quad y \quad$ Proyectos. 1982. $<$ www.blest.eu/doxa/garreton82.html >.

- "Seis proposiciones sobre redemocratización en Chile." Documento de Trabajo 314, Flacso, septiembre 1986a.

—. "Y fue el año decisivo." Apsi, del 15 al 28 de diciembre, 1986b.

—. "1986-1987. Entre la frustración y la esperanza. Balance y perspectivas de la transición a la democracia." Documento de Trabajo 329, Flacso, enero 1987a,

- "Las complejidades de la transición invisible. Movilizaciones populares y rég imen militar en Chile." Documento de Trabajo 334, Flacso, abril $1987 \mathrm{~b}$.

—. "Política y sociedad en la marginación e integración del mundo popular. Notas para un esquema de análisis." Material de Discusión 95, Flacso, marzo 1987c.

- "Reconstrucción y democracia. La doble problemática del sistema político chileno." Documento de Trabajo 364, Flacso, diciembre 1987d.

-. "La democracia que se inaugura y sus condiciones socio-políticas." Convergencia 17, enero-marzo 1990: 13-18.

- La redemocratización política en Chile: transición, inauguración y evolución. Santiago: Flacso, 1993.

—. "Movimientos sociales y procesos de democratización. Un marco analítico (1)." Excerpta 2, abril 1996.

—. "Entrevista: 'Hay que construir un nuevo sujeto político'." Página 12, 31 de diciembre de 2012.

Gaudichaud, Frack. "Pensar las alternativas y el socialismo en la América Latina del siglo XXI. Reflexiones y lecciones sobre la Unidad Popular, el 'poder popular' y el proceso revolucionario chileno." Ponencia a presentar en la II Conferencia 
Internacional "La obra de Carlos Marx y los desafíos del siglo XXI". La Habana, del 4 al 8 de mayo de 2004.

- Poder Popular y Cordones Industriales. Testimonios sobre el movimiento popular urbano, 1970-1973. Santiago: LOM Ediciones, 2004.

Godoy, Óscar. "La transición chilena a la democracia: pactada." Estudios Públicos 74 (1999): 79-106.

Guerrero, Manuel. "El conjuro de los movimientos sociales en el Chile neoliberal." Revista Venezolana de Economía y Ciencias Sociales 12/2 (2006):147-156.

Harnecker, Marta. "Reflexiones sobre el gobierno de Allende: estudiar el pasado para construir el futuro." 2003

$<$ www.biblioteca.clacso.edu.ar/clacso/otros/20111026114216/allende.pdf $>$.

Iglesias, Mónica. Rompiendo el cerco. El movimiento de pobladores contra la dictadura. Santiago: Radio Universidad de Chile, 2011.

Illanes, María Angélica. La batalla de la memoria. Ensayos históricos de nuestro siglo. Chile 1900-2000. Santiago: Planeta/Ariel, 2002.

Lechner, Norbert. "La democratización en el contexto de una cultura posmoderna." Cultura política y democratización, comp. Nobert Lechner. Santiago: Flacso/Clacso/ICI, 1987: 253-262.

—. "Los nuevos perfiles de la política. Un bosquejo." Nueva Sociedad 130 (1994): 3243.

Leiva, Sebastián. "El MIR y los Comandos Comunales: poder popular y unificación de la movilización social". Cyber Humanitatis 30 (2004).

Löwy, Michael. "Los actores olvidados de la Unidad Popular." Poder Popular y Cordones Industriales. Testimonios sobre el movimiento popular urbano, 1970 1973, ed. Frack Gaudichaud. Santiago: LOM Ediciones, 2004: 11-12.

Marín, Juan Carlos. "Las tomas (1970-1972)." Marxismo y Revolución 1, julioseptiembre de 1973: 49-77.

Marini, Ruy Mauro. "El viaje de Todman. Éxito en Chile, fracaso en Brasil." El Universal, 24 de agosto de 1977: 4.

Moulian, Tomás. Chile Actual: Anatomía de un mito. Santiago: LOM Ediciones/Arcis, 1997.

- "Tomás Moulian: itinerario de un intelectual chileno. Entrevista de Emir Sader, Juan Carlos Gómez Leyton y Horacio Tarcus." Crítica y Emancipación: Revista Latinoamericana de Ciencias Sociales 1 (2008): 129-174.

O'Donnell, Guillermo. "La consecución de la democracia: una lucha en un proceso incesante que ha de saber ganarse (entrevista de Joaquín Támara)." DHIAL Desarrollo Humano e Institucional de América Latina 17 (2001). 
- Contrapuntos. Ensayos escogidos sobre autoritarismo y democratización. Buenos Aires: Paidós, 2004.

Razeto, Luis. "La economía de solidaridad en un proyecto de transformación social." Proposiciones 14 (1987): 44-54.

—. Las organizaciones económicas populares 1973-1990. Santiago: PET, 1990.

Retamozo, Martín. "Lo político y la política: los sujetos políticos, conformación y disputa por el orden social." Revista Mexicana de Ciencias Políticas y Sociales LI/206, (2009): 69-91.

Ruiz, Carlos. "Actores sociales y transformación de la estructura social." Revista de Sociología 21 (2007): 209-233.

Salazar, Gabriel. "De la generación chilena del '68: ¿Omnipotencia, anomia, movimiento social?" Proposiciones 12 (1986): 96-116.

—. "El viejo "pacto social" del librecambismo." Revista Central de Sociología 2 (2007): 11-28.

Santos, Theotonio dos. “¿Podemos triunfar?” Chile Hoy 58 (1973): 4.

Streeck, Wolfgang. "Los ciudadanos como clientes. Consideraciones sobre la nueva política de consumo." New Left Review 76 (2012): 23-41.

Tironi, Eugenio. "Marginalidad, movimientos sociales y democracia." Proposiciones 14 (1987): 9-20.

—. Autoritarismo, modernización y marginalidad. Santiago: Ediciones SUR, 1990.

—. La irrupción de las masas y el malestar de las elites. Chile en el cambio de siglo. Santiago: Grijalbo, 1999.

—. "Los Comunistas." El Mercurio, 18 de junio de 2013.

Unidad Popular. Programa Básico de Gobierno de la Unidad Popular. Santiago, 1970.

Valdivia, Verónica. “'Crónica de una muerte anunciada': La disolución del Partido Nacional, 1973-1980." Su revolución contra nuestra revolución. Izquierdas y derechas en el Chile de Pinochet (1973-1981), ed. Verónica Valdivia, Rolando Álvarez y Julio Pinto. Santiago: LOM Ediciones, 2006: 15-47.

Vasconi, Tomás Amadeo. Las Ciencias Sociales en América del Sur y Chile, 19601990. Santiago: Centro de Investigaciones Sociales/Arcis, 1991.

Winn, Peter. Tejedores de la revolución. Los trabajadores de Yarur y la vía chilena al socialismo. Santiago: LOM Ediciones, 2004. 